\title{
Nonsubstitution Theorems for a Small Trading Country
}

\author{
Theodore C. Bergstrom \\ 1996 for Pacific Economic Review
}

\section{Introduction}

One of the elegant gems of modern economic theory is Paul Samuelson's nonsubstitution theorem. Samuelson (1951) showed that a surprisingly rich class of closed economies behave in general competitive equilibrium as if production were of the Leontief fixed coefficient form. Though Samuelson's assumptions allow the possibility of neoclassically smooth substitution among many inputs, his nonsubstitution theorem is thought to be of limited practical application because it must assume that there is only one non-produced factor of production and no joint production. The first assumption rules out any reasonable treatment of an economy with significant agricultural and mining sectors, while the lack of joint production makes it difficult to treat intertemporal issues adequately. In a later paper (1961), Samuelson pointed out that the nonsubstitution theorem extends to an economy with several non-produced factors so long as all factors but one can be purchased in arbitrary quantities at a fixed price.

In international trade theory, a country is said to be "small" if its market activities can be assumed to have no effect on prices of internationally traded commodities. Samuelson's 1961 nonsubstitution theorem could be interpreted directly as a theorem about small trading countries which have neither an agricultural nor a mining sector. Perhaps Hong Kong or Singapore is an example of such a country. Remarkably, the nonsubstitution theorem can be extended to a much larger class of small countries. In this paper, I will prove a nonsubstitution theorem for small countries in which there may be many nontradeable goods, including nonproduced factors of production, such as land and minerals. The assumptions allow joint production and the use of nontraded goods as inputs. Of course, some restrictive assumptions are required, but the class of economies included appears to be broad enough to permit a great deal of descriptive realism.

In a closed economy where Samuelson's nonsubstitution theorem applies, not only are factor proportions determined independently of final demand and of the endowment of labor, but so are the equilibrium prices of all produced goods relative to the wage rate of labor. In fact, the production possibility frontier is linear with slopes proportional to the equilibrium prices of the corresponding 
commodities. In a small country which satisfies the assumptions of the most general theorem found in this paper, the production possibility frontier can be curved, but the consumption possibility frontier that is found after allowing for international trade will be a hyperplane. Output prices and the wage of labor will be determined independently of demand and of factor endowments. The prices of factors other than labor may depend on endowments of these factors but are independent of demand. For some interesting special cases of our model, equilibrium prices of all factors are independent of factor endowments.

It is interesting to compare these nonsubstitution results to the classical factor-price equalization theorems of Samuelson (1948), (1967), and of Lionel McKenzie (1958). The factor-price equalization theorems state conditions under which the prices of non-traded factors are determined by the prices of traded goods, independently of demand and of factor endowments. The nonsubstitution theorems in this paper allow the possibility that factor prices may depend on endowments, but require that the prices of nontraded factors do not depend on the nature of demand, but are completely determined by the prices of traded goods and the endowments of factors. Because a nonsubstitution theorem draws a weaker conclusion, it can use weaker assumptions than a factor-price equalization theorem. The standard factor-price equalization theorems must assume that the number of factors not exceed the number of traded commodities. Where there are more than two goods and factors, these theorems also need strong and economically unappealing assumptions about the Jacobian of the system of cost functions that are not needed for the general nonsubstitution theorems found here.

Factor price equalization theorems have a great fascination because if their conclusions are true, then differences in real wages from country to country can not be attributed to differences in factor endowments. Any differences that can not be explained by differences in human capital would disappear in the absence of tariffs and other interference with free competition domestically and internally. It is widely believed that the assumptions required for factor-price equalization theorems are to strong to be even approximately true in the real world. The nonsubstitution theorems discussed here, like the classical factor price equalization theorems, conclude that the prices of all produced goods and the wages of labor must equalize in two countries that face the same prices for tradeables and have access to the same manufacturing technology. But the nonsubstitution theorems reach this conclusion from weaker and more economically appealing assumptions than the factor price-price equalization theorems. This suggests that the competitive forces for equalization of real wages among countries are much more robust than is usually believed.

For small countries, nonsubstitution theorems, like factor price equalization theorems, are of great practical usefulness because they simplify general equilibrium comparative statics. In fact, for many purposes, the simplifications made possible by a nonsubstitution theorem are as useful as those that would follow from a factor price equalization theorem. We will illustrate this point in our later discussion of applications. 


\section{Some Special Cases}

Before presenting general results, we examine some simple models which are interesting in their own right and which illustrate the ideas underlying our general theorem.

\section{A three-sector, Two-factor Model}

Consider a small country with three sectors, agriculture, manufacturing, and services. Production in each sector is described by a well-behaved neoclassical production function which is homogeneous of degree one. There are two nonproduced factors of production, labor and land. Labor is fully mobile among sectors, while land is useful only in agriculture. Positive output of manufactured goods requires some labor and positive output of agricultural goods requires some land. All three produced commodities can be used as inputs in the other industries. Agricultural and manufactured output can be traded internationally at world prices, but factors and services can not be exported or imported. Consumers are interested in all three produced commodities but do not consume labor or land directly. ${ }^{1}$

The production functions of the three industries can be written as follows:

$$
\begin{array}{rc}
\text { Agriculture: } & X_{A}=F_{A}\left(L_{A}, T, X_{M A}, X_{S A}\right) \\
\text { Manufacturing : } & X_{M}=F_{M}\left(L_{M}, X_{A M}, X_{S M}\right) \\
\text { Services : } & X_{S}=F_{S}\left(L_{S}, X_{A S}, X_{M S}\right)
\end{array}
$$

where $L_{i}$ is the amount of labor used in the $i$ th sector, $T$ is the total endowment of land, and $X_{i j}$ is the amount of commodity $i$ used in production of commodity $j$.

Since there are constant returns to scale, competitive equilibrium requires that if a good is produced, its price must equal its unit cost of production. Let $\mathrm{w}$ and $\mathrm{r}$ denote the factor prices of labor and land. Let $p_{A}, p_{M}$, and $p_{S}$ denote the prices of final goods in agriculture, manufacturing, and services, respectively. Competitive prices and unit costs must satisfy the following:

$$
\begin{array}{rll}
p_{A} \leq C_{A}\left(w, r, p_{M}, p_{S}\right) & \text { with equality if } & X_{A}>0 \\
p_{M} \leq C_{M}\left(w, p_{A}, p_{S}\right) & \text { with equality if } & X_{M}>0 \\
p_{S} \leq C_{S}\left(w, p_{A}, p_{M}\right) & \text { with equality if } & X_{S}>0
\end{array}
$$

Suppose that all three final goods are produced, so that 4-6 hold with equality and recall that $p_{A}$ and $p_{M}$ are determined exogenously. Equations 4, 5, and

\footnotetext{
${ }^{1}$ This simple model is similar to a trade model with nontraded goods that was introduced by Komiya. Our model generalizes Komiya's in allowing produced goods to be used as inputs but is more special in requiring that one of the factors is useful only in one of the sectors. Komiya generalizes the latter assumption to the weaker assumption that there are no factor intensity reversals. We could follow him in that regard, but our stronger assumption suggests a useful generalization to the case of many factors and goods.
} 
6 have a convenient recursive structure that enables us to solve uniquely for the factor prices and the price of services, independently of factor endowments and of demand. If we substitute the right side of Equation 6 for $p_{S}$ in Equation 5, then the right side of Equation 5 is expressed as a function of $w$ and the predetermined variables, $p_{A}$ and $p_{M}$. In fact, since the cost functions $C_{M}$ and $C_{S}$ are monotone increasing in their arguments, it must be that this expression is a monotone increasing function of $w$. Therefore for given $p_{A}$ and $p_{M}$, there can be only one value of $w$ that simultaneously satisfies Equations 5 and 6 . Given $w, p_{A}$, and $p_{M}$, Equation 6 determines $p_{S}$. Finally, since the right hand side of Equation 4 is monotone increasing in $r$ and since all of the other variables in Equation 4 have been determined, there can be only one value of $\mathrm{r}$ consistent with Equations 4-6. Even if agricultural output were zero in equilibrium, the competitive rent of land would be uniquely determined. Since land is useful only in agriculture, land would be in excess supply if agricultural output were zero. Therefore its price would have to be zero. Since production functions are assumed to be smooth, concave, and homogeneous of degree one, factor proportions and input output coefficients in each industry are uniquely determined by factor prices. It follows that not only are the prices of factors and of services determined by the prices of tradeables, but so are input-output coefficients in every industry.

For the economy of this section we have demonstrated that there is a factor price equalization theorem as well as a nonsubstitution theorem. We summarize these results as follows.

Proposition 1 In the three sector, two factor model discussed above, if there is positive output in manufacturing and services, then the prices of all nontraded goods and factors are determined by the prices of the two tradeable goods. So long as all three goods are produced, input-output coefficients in each industry are determined by the prices of tradeables, independently of demand or of factor endowments.

\section{A Specific Factors Model}

Let us consider a simple generalization of the three-sector, two-factor economy. Instead of a single industry, agriculture, let there be several industries constituting the extractive sector of the economy. This sector could include a number of agricultural and mining industries as well as some manufacturing industries which happen to use nontradeable factors as inputs. All outputs of the extractive sector will be assumed to be internationally tradeable. As before, all production is described by smooth, neoclassical single output production functions with constant returns to scale. All produced goods may be used as inputs in the production of other goods. Labor can be used in the production of every good. The other nonproduced factors of production are industry specific. Each factor other than labor is useful as an input in only one industry and each extractive industry uses only one nonproduced factor other than labor. As in the previous section, there is a manufacturing industry and a service industry. The 
only inputs used in these industries are labor and produced goods.

Reasoning exactly as we did in the previous section, we find that the wage of labor and the price of services are determined by the world prices of tradeable goods, independently of domestic demand and factor endowments. Therefore for each extractive industry, the price of output and the prices of all inputs other than the specific factor are determined. Unit costs of any extractive commodity must be a monotone increasing function of the price of the factor specific to that commodity. In equilibrium, in each extractive industry either price equals unit cost or output equals zero. In the latter case, the rental price of the factor specific to the industry is zero. In the former case, the rental price of the specific factor is the unique price which equalizes unit costs in the industry to the price of output. As in the previous section, since all factor prices are determined and production functions are smooth and homogeneous of degree one, it must be that input- output proportions are determined. Therefore the specific factors model presented here admits a nonsubstitution theorem and a factor price equalization theorem.

Proposition 2 In the specific factors model of this section, if manufacturing and services both produce positive output in competitive equilibrium, then all factor prices, the price of services and the input output coefficients in every industry are determined by the price of tradeable goods, independently of domestic demand and of factor endowments.

It is interesting to compare this specific factors model with the so-called Ricardo-Viner model which Samuelson (1971) introduced as:

"an alternative simple model that can free the discussion from the straight jacket of the box diagram which Stolper and I imposed on the trade literature decades ago."

Like our specific factors model, the Ricardo-Viner model allows many goods and many nontradeable factors of production. Both models exclude joint production and assume a neoclassical production function for each good. All produced goods are tradeable in international markets. Our model generalizes the Ricardo-Viner model by allowing a full interindustry structure with intermediate goods whereas the Ricardo-Viner model has only one mobile factor. On the other hand, our nonsubstitution theorem makes the additional assumption that there is some active industry that uses no specific factors. Despite the added generality in other directions, this assumption yields much stronger implications about the nature of equilibrium than does the Ricardo- Viner model. For example, in our model there is full factor price equalization while Samuelson shows that the Ricardo-Viner model only implies "partial" factor price equalization.

\section{A Neoclassical Model with More Factors than Tradeable Goods}

This section presents an economy in which there is nonsubstitution but where there need not be full factor price equalization. As in our first model, let there be 
three industries, agriculture, manufacturing and services. Production functions for the three industries can still be described by Equations 1-3 above, where the expression $T$ in Equation 1 is an $n$-vector specifying the quantity of each of $n$ kinds of land used in agriculture. As before, we assume that the function $F_{A}$ is concave, homogeneous of degree one, and twice continuously differentiable. In addition we will assume that for a fixed vector of land, the total possible output is bounded and that the Hessian matrix of second order partial derivatives of $F_{A}$ with respect to the inputs other than land is negative definite. ${ }^{2}$ The cost functions can be described by Equations 4-6, above, where the expression $r$ in Equation 4 represents the vector of factor prices for the $n$ different kinds of land.

As in the earlier section, Equations 5 and 6 uniquely determine the wage rate $w$ and the price $p_{S}$ of services, as a function of the prices of tradeables. However, the single equation, 4 , can not possibly determine all of the $\mathrm{n}$ factor prices in the vector $r$. In general, these prices will depend on the relative endowments of the various kinds of land. However, since land is useful only in agriculture, the quantity of each kind of land available to agriculture is determined by the endowment. Since prices of the nonland inputs are determined by the prices of tradeables, the quantities of these inputs used in agriculture will be determined by the prices of tradeables and the endowment of each kind of land. Given the quantities of all inputs, the marginal value product of each kind of land is determined and is equal to its rental price. This informal argument can be made with rigor and elegance, using the notion of the variable profit function which was introduced by Terence Gorman $(1968)^{3}$ and Ervin Diewert (1973) and is defined as follows:

$$
\begin{aligned}
& V_{A}\left(w, p_{A}, p_{M}, p_{S}, T\right)= \\
& \quad \sup \left\{p_{A} F_{A}\left(L_{A}, T, X_{M A}, X_{S A}\right)-w L_{A}-p_{M} X_{M A}-p_{S} X_{S A}\right\}
\end{aligned}
$$

where the supremum is taken over the set of nonnegative values of $L_{A}, X_{M A}$, and $X_{S A}$. The value of the variable profit function at given prices and endowment of land is the maximum amount of profit that the industry can make with the endowment $T$ of land after it has paid the variable factors but not the fixed factors. Gorman and Diewert show that for given prices of variable factors, the variable profit function is concave and linearly homogeneous in the fixed factors. They also demonstrate that where production functions are strictly convex, the gradient of the variable profit function with respect to the prices of variable factors is the negative of the vector of quantities of variable inputs. They also show that the vector of equilibrium prices of fixed factors must be equal to the gradient of the variable profit function with respect to quantities of fixed factors whenever this gradient exists. If production functions are twice continuously differentiable, then the gradient of the function $V_{A}$ with respect

\footnotetext{
${ }^{2}$ This last assumption is slightly stronger than the assumption that production is strictlyconcave in the non-land inputs. We make the stronger assumption at this point to avoidinessential mathematical complications.

${ }^{3}$ Gorman called this function the gross profit function.
} 
to $T$ exists. ${ }^{4}$ Therefore, since the prices of the other inputs are determined from international prices, the quantities of variable factors and the prices of fixed factors are uniquely determined by international prices and the endowment vector, $T$. Since $V_{A}$ is homogeneous of degree one in $T$, its gradient must be homogeneous of degree zero in $T$. Therefore multiplying the entire land endowment vector by a positive constant leaves the equilibrium rental prices of all types of land unchanged. The results of our reasoning are summarized in Proposition 3.

Proposition 3 In the model of this section, if there is positive output in manufacturing and in services, then the wage of labor, the price of nontradeables and the input-output coefficients in manufacturing and services are determined by the prices of tradeables, independently of demand and of factor endowments. The price of each type of land and the amounts of each input and output in agriculture are determined by the prices of tradeables and the vector of land endowments, independently of demand. Proportionate changes in the vector of endowments of land leave all factor prices unchanged.

These results can be easily extended to the case of an economy with many different agricultural and mining industries, each of which satisfies the assumptions made for the single agricultural industry treated above. All that needs to be done is to treat the collection of industries that use some land as a single aggregate industry whose output is the total value at world prices of the outputs of the individual industries and where inputs are just total quantities of inputs to the individual industries in this sector. Since the prices of the various outputs are independent of their quantities, the aggregate production function defined in this way can be shown to inherit all of the mathematical properties that we have assumed for the individual production functions and Proposition 3 can be applied directly.

\section{On the Existence of Diversified Competitive Equilibrium}

All of the nonsubstitution and factor price equalization results in this paper depend on the assumption that the economy does not specialize in agriculture and nontraded goods. If the economy is diversified in this sense, then factor prices are independent of demand and possibly also of factor endowments. The difficulty is that factor endowments and demand do determine whether a country specializes or not. The theorems in this paper would not be very interesting if, for example, it turned out that "most" endowments resulted in specialization, or if it were difficult to tell whether specified changes in the economic

\footnotetext{
${ }^{4}$ From negative definiteness of the Hessian matrix for nonland inputs and the implicit function theorem, it can be shown that the quantity of variable factors which maximizes variable profits is a differentiable function of the vector of fixed factors. Therefore since output and hence profit is differentiable in factor inputs it follows that $V_{A}$ is differentiable with respect to the vector of fixed factors.
} 
environment would lead the economy from diversification to specialization or vice versa. Fortunately, the conditions required for a small country to have a diversified competitive equilibrium are not delicate. In fact, for a country with a specified endowment and distribution of ownership of resources and given consumer preferences, there is a threshold amount of labor such the economy will produce manufactured goods if and only if its labor endowment exceeds that threshold.

Consider the neoclassical model of the previous section. We have argued that if there is diversification, the prices of tradeables and the vector of endowments of land uniquely determine the prices of nontradeable factors and outputs, the input-output coefficients in each sector, and the quantities of each input and output of the agricultural sector. In particular, if the country is diversified, the total amount of labor required by the agricultural sector is uniquely determined by international prices and the endowments of land. Since services cannot be imported or exported, if there is to be diversification, the country must have at least enough labor to supply the labor requirements of the service sector as well as of agriculture. Since the prices of all factors and goods are determined by the prices of tradeables and the endowment of land and since incomes are determined by the prices of goods and factors, total domestic demand for services is also determined if there is specialization. Input-output coefficients in each industry are determined according to Proposition 3, so that, knowing the consumer demand for services, we can calculate the amount of labor needed to produce these services. Also, we can find the amount of labor needed to produce the services which are used as inputs in agriculture. Let $L_{A}, L_{S}$, and $L_{S A}$ denote the amounts of labor that at the prices consistent with diversification are demanded respectively, by agriculture directly, by services directly, and by agriculture indirectly to produce services used by agriculture.

Clearly, in order for there to exist a diversified competitive equilibrium, the small country must have a labor endowment $L$ exceeding $L_{A}+L_{S}+L_{S A}$. If $L<L_{A}+L_{S}+L_{S A}$, then the country must specialize in agriculture and services. The amount of labor used in agriculture will be less than the amount required at the prices leading to diversification. The wage of labor will be higher than it would be if there were diversification and manufacturing will be unprofitable. This seems a reasonable description of the state of affairs in newly settled countries like the United States or Australia in the nineteenth century. As immigration to these countries proceeded, the marginal product of labor on the land was driven down to the point where wages were roughly equalized to wages in the industrial world and a manufacturing sector arose.

Given our other assumptions, the condition that $L<L_{A}+L_{S}+L_{S A}$ is sufficient as well as necessary for a diversified competitive equilibrium to exist. The remaining labor, $L-L_{A}-L_{S}-L_{S A}$ will be absorbed by the manufacturing sector, either directly as an input or indirectly as an input into services used in manufacturing. Since input-output coefficients at the prices sustaining diversification are predetermined, the output of manufacturing that will absorb this quantity of labor is also uniquely determined. To see that the quantities we have solved for actually constitute a competitive equilibrium, we reason as 
follows. Total consumer income in the economy equals total payments to the factors, labor and land. Since each consumer must obey a budget constraint, the value of aggregate consumption must equal total consumer income. Constant returns to scale and the fact that services are nontraded implies that the value of services consumed or used as inputs in other sectors equals the value of labor and tradeable inputs used in that sector. Subtracting the latter equality from the former, we find that the value of exports equals the value of imports. Factor prices are by construction set to equalize supply and demand in factor markets. Therefore the prices and quantities which we have found constitute a competitive equilibrium.

\section{A General Nonsubstitution Theorem}

\section{Informal Discusssion}

The nonsubstitution results of the last section can be powerfully generalized. We can accommodate many commodities, some of which are traded in world markets and some of which are nontradeables that can be neither exported nor imported. There can be joint production. The number of nontraded factors can be larger than the number of traded commodities. All produced goods can be used as inputs in production of any other goods. Production is assumed to satisfy constant returns to scale and the usual convexity assumption.

Since joint production is allowed, the concept of an "industry" is not clearly defined. Instead of defining industries, we assume that the economy has three sectors, each of which may produce several outputs. These three sectors will play roles similar to those played by agriculture, manufacturing, and services, respectively in our simple models. Sector 1 can use any commodity, produced or nonproduced, traded or nontraded, as an input. Firms in Sector 1 can produce multiple outputs, so long as these outputs are all tradeable. Sector 2 produces only tradeable goods but can use any tradeable or nontradeable produced goods as inputs. The only nonproduced input allowed in Sector 2 is labor. In Sector 3, which produces nontradeable goods, there are assumed to be no joint products. Labor and produced goods (both tradeable and nontradeable) can be used as inputs, but no nonproduced factors other than labor are used in this sector.

Our assumptions about Sector 1 allow a great variety of possible technologies and they permit much more realistic modelling of agriculture and mining than is usual in trade models. In agriculture, there may be many crops and many types of farmland each with its own peculiar suitability for various crops. Likewise, the mining industry may have access to many different types of deposits having different extraction costs and different qualities of minerals. Sector 1 may also include "old" manufacturing industries where production continues only because there is fixed plant and equipment in place which would not be replaced at current prices. This economically obsolete equipment can be treated as part of the stock of factors in fixed supply.

The principal assumption imposed on Sector 2 is that this sector uses no 
nonproduced factors other than labor. While this is a strong assumption, it does not need to be true of the entire manufacturing sector. All we ask is that some industry or group of industries operate at nonzero output and use no nonproduced, nontradeable factors. Later we show that this even this assumption can be usefully weakened.

The nontradeable sector is more restrictively modelled. This sector is not allowed to use non-produced factors other than labor and no joint production is allowed. ${ }^{5}$ These assumptions seem reasonable in the case of nontradeables such as services and leisure ${ }^{6}$ where the input of land is negligible. To ignore the use of land in retail trade and in transportation is more questionable, but doing so seems justified at least as a first approximation. Because our model allows nontradeable goods to be used as inputs in all industries, we do not have to assume away domestic transportation costs.

\section{A Formal Statement}

Consider a small country engaged in international trade. There are $T$ tradeable commodities which can be traded internationally at world prices which are independent of market activity in the small country. There are $N$ nontradeable commodities which can be neither exported nor imported (but can be freely traded domestically). Finally, there are $F$ factors in fixed supply which can not be produced or imported. The $F$ th factor is called labor.

Technology is described by the standard activity analysis formulation. There is a set $Y$ of $T+N+F$ dimensional vectors denoting feasible transformations of commodity vectors. By convention, a $T+N+F$ vector $y$ in the set $Y$ represents a transformation of commodities in the following way. The first $T$ components of $y$ are net outputs (inputs if negative) of tradeable goods. The next $N$ components are net outputs (inputs if negative) of nontradeable produced commodities. For feasible $y$, the last $F$ components must be non-positive and represent net factor inputs. The economy can also be decomposed into three sectors, each with its own net production possibility set $Y_{i}$ in such a way that $Y=Y_{1}+Y_{2}+Y_{3}$. These production possibility sets satisfy the following assumptions.

Assumption 0 (Constant returns, convexity, and continuity.) The sets $Y_{i}$ are closed convex cones for $i=1,2,3$.

Assumption 1 (Sector 1 does not produce nontradeables.) If $y \in Y_{1}$ then $y_{j} \leq 0$ for $T<j<\leq T+N+F$.

Assumption 2 (Sector 2)

A. (Sector 2 uses labor but no other nonproduced factors.) If $y \in Y_{2}$ and $y \neq 0$, then $y_{j}=0$ for $T+N<j<T+N+F$ and $y_{T+N+F}<0$.

\footnotetext{
${ }^{5}$ The no-joint-production assumption could be usefully weakened along lines suggested by A. D. Woodland (1977).

${ }^{6}$ It is convenient to treat leisure as a nontradeable commodity which is produced with labor as its only input. In this way we can maintain the convention of a fixed total supply of labor while permitting consumers to choose between leisure and other goods in the usual way.
} 
B. (Sector 2 does not produce nontradeable goods.) If $y \in Y_{2}$ then $y j \leq 0$ for for $T<j \leq T+N$.

Assumption 3 (Sector 3 satisfies Samuelson's 1961 nonsubstitution theorem.)

A. (No joint production, convexity and constant returns to scale.) There exist closed convex cones, $Y_{31}, \ldots, Y_{3 M}$ such that $Y_{3}=Y_{31}+\ldots+Y_{3 M}$. For each $i$,if $y \in Y_{3 i}$, then $y_{j} \leq 0$ for all $j \neq i$.

B. (Labor is the only nonproduced input in production of nontradeables.) If $y \in Y_{3}$ then $y_{j}=0$ for $T+N<j<T+N+F$

C. (Possibility of positive net output of nontradeables.) There exists $y \in$ $Y_{3}$ such that $y_{j}>0$ for all $j$ such that $T<j \leq T+N$.

Competitive prices in this economy are denoted by the $T+N+F$ vector $p=\left(p_{t}, p_{n}, p_{f}\right)$ where $p_{t}$ is the $T$ vector of world prices for tradeables, $p_{n}$ is the $N$ vector of prices of nontradeables, and $p_{f}$ is the $F$ vector of prices of factors. The wage of labor, $w$, is the last component of $p_{f}$. For each sector $i=1,2,3$, let $y_{i}^{*}$ be the $T+N+F$ vector denoting the equilibrium net output vector of sector $i$. Then $y^{*}=y_{1}^{*}+y_{2}^{*}+y_{3}^{*}$ is the vector of net production of the economy as a whole. It is also sometimes convenient also to write $y^{*}=\left(y_{t}^{*}, y_{n}^{*}, y_{f}^{*}\right)$ where $y_{t}^{*}, y_{n}^{*}$, and $y_{f}^{*}$ are respectively, net output vectors of tradeables, nontradeables and factors for the small country. Let $c_{t}$ and $c_{n}$ be the vectors of tradeable and nontradeable goods consumed directly by citizens of the country. We assume that incomes of all consumers are determined once the vector $p$ of prices of goods and factors is known. The distribution of income together with the prices of consumption goods determines aggregate demand for consumer goods in the country. Let $D_{t}(p)$ and $D_{n}(p)$ denote respectively the country's aggregate demand functions for tradeable and nontradeable goods.

A competitive equilibrium for a small trading country consists of a price vector, $p=\left(p_{t}, p_{n}, p_{f}\right)$, net output vectors $y_{i}^{*}$ for $i=1,2,3$,and consumption vectors $c_{t}$ and $c_{n}$ such that the following conditions are satisfied:

1. (Profit maximization) For $i=1,2,3, y_{i}^{*}$ maximizes the value of Sector $i^{\prime}$ s net output, $p y_{i}$, on the feasible set $Y_{i}$.

2. (Trade balance) Where $c_{t}=D_{t}(p)$ is the vector of tradeables demanded by consumers, $p_{t}\left(c_{t}-y_{t}^{*}\right)=0$.

3. (Equilibrium in nontradeables) Where $c_{n}=D n(p)$ is the vector of nontradeables demanded by consumers, $c_{n}=y n^{*}$.

4. (Equilibrium in factors) Where $v$ is the vector of aggregate initial holdings of factors, $y_{f}^{*}=-v$.

Conditions 1-4 simply apply the standard definition of competitive equilibrium to the special economy treated here. Competitive profit maximizing behavior by producers requires that the value of net outputs of each sector be maximized. The vector of net imports (where by notational convention, exports 
are negative imports) is just $c_{t}-y_{t}$. Therefore, condition 2 states that the value of imports equals the value of exports. Since nontradeables are neither imported nor exported, condition 3 requires that net production of nontradeables equals total consumption. Since factors are not produced or traded internationally, condition 4 requires that the amount of factors used in production must equal the supply initially available.

Now we can state a general nonsubstitution theorem.

Theorem 1 Suppose that Assumptions 0-3 are satisfied. In any competitive equilibrium where Sector 2 pursues some nonzero activity and where positive amounts of each nontraded good are produced:

- Competitive equilibrium prices of all nontradeable goods and the wage of labor are determined by the price of tradeable goods independently of demands and of factor endowments.

- For almost all vectors of factor endowments, competitive equilibrium prices of nonproduced factors other than labor are determined by the prices of tradeable goods and by domestic factor endowments, independently of demand and of the endowment of labor.

- The equilibrium prices of nonproduced factors are invariant to equiproportional changes in their endowments.

If production can be described by strictly quasi-concave single output production functions as in standard neoclassical theory, then the cost minimizing input proportions in each sector of the economy are uniquely determined by the prices of the inputs. This observation generalizes to joint production in the following way. Production in Sector 1 will be said to be strictly convex in variable factors if all convex combinations of any two elements $\left(y_{1}, T\right)$ and $\left(y_{2}, T\right)$ of $Y_{1}$ are in the interior of $Y_{1}$. As we will prove, the following is a straightforward consequence of Theorem 1.

Corollary 1 If the assumptions of Theorem 1 hold, and if production is Sector 1 is strictly convex in the variable factors, then quantities of inputs used in Sector 1 are determined by the price of tradeables and the endowment of nonlabor fixed factors.

\section{Proof of a General Nonsubstitution Theorem}

The proof of our general nonsubstitution theorem is similar to the proof of Proposition 3. First we show that the wage of labor and the prices of nontradeable produced goods are determined by the zero-profit conditions in sectors 2 and 3 . Then we show that since the entire endowment of nonproduced factors other than labor is assumed to be used in Sector 1, the vector of rental prices of nonproduced factors can be found as the gradient of the variable profit function for that sector.labor are determined We proceed with our formal proof by means of a series of lemmas. 
Lemma 1 (Samuelson's 1961 nonsubstitution theorem) If Sector 3 produces a positive output of each nontradeable good, then for a given wage rate of labor and given prices of tradeable goods, there is exactly one price vector for nontradeables such that prices of all nontradeables equal unit costs.

\section{Proof of Lemma 1}

The assumptions for Sector 3 are precisely those made by Samuelson for his 1961 nonsubstitution theorem. Although this theorem is announced in his 1961 paper, the paper does not include a proof. However, the theorem can be deduced as a simple corollary to his 1951 nonsubstitution theorem. In particular, for any wage rate of labor, the model in which factors other than labor can be imported at constant prices is isomorphic to a model in which these factors can be produced using labor alone with constant returns to scale. This latter model is a special case of an economy satisfying the conditions of the 1951 theorem and the conclusion of the 1961 theorem is immediate from this application. There are several proofs of the 1951 theorem in the literature.

Lemma 2 (Monotonicity of prices of nontradeables) For fixed prices of tradeable goods and for wage rate $w$, let $p_{n}(w)$ be the unique price vector for nontradeables at which prices of all nontradeables equal unit costs of production. Then every component of $p_{n}(w)$ is an increasing function of $w$.

\section{Proof of Lemma 2}

Since there are constant returns to scale, it must be that in competitive equilibrium, the price of each nontraded good is equal to its unit cost of production. Since labor is the only factor in fixed supply which is used in production of nontradeables, production costs depend only on the prices of produced goods and the wage of labor. Therefore we can write the cost function for any nontradeable good $j$ as $C_{j}\left(p_{t}, p_{n}, w\right)$. Let $p_{n j}(w)$ denote the $j$ th component of $p_{n}(w)$. Suppose that $w^{*}>w$. Consider a nontradeable good $k$ such that the ratio $\rho=p_{n k}(w *) / p_{n k}(w) \leq p_{n j}(w *) / p_{n j}(w)$ for all other nontradeables $j$. Since cost functions are homogeneous of degree one in prices it must be that $p_{n k}\left(w^{*}\right)=\rho p_{n k}(w)=C_{k}\left(\rho p_{t}, \rho p_{n}(w), \rho w\right)$. Suppose that $\rho<1$. Then since cost functions are increasing in prices, it must be that $C_{k}\left(\rho p_{t}, \rho p_{n}(w), \rho w\right)<C_{k}\left(p_{t}, p_{n}(w *), w *\right)=p_{n k}\left(w^{*}\right)$. But this inequality contradicts the equation above. It follows that $\rho>1$. This proves the lemma.

(Uniqueness of wage rate) For fixed prices of tradeable goods there is only one wage rate for labor consistent with competitive equilibrium and nonzero activity in Sector 2.

Proof of Lemma 3

Since there are constant returns to scale in Sector 2, it must be that if some non-zero activity is undertaken in this sector, then the maximum profits attainable by a nonzero activity in this sector must be zero. By assumption, every non-zero activity, $y \in Y_{2}$, must use a positive amount of labor as an input and nontradeable goods can be used as inputs but cannot be outputs of Sector 2. From Lemma 2 it follows that where $p_{n}=p_{n}(w)$, the profitability of every 
nonzero activity in $Y_{2}$ is a strictly decreasing function of $w$. Therefore there can be only one wage rate at which the most profitable non-zero activity in $Y_{2}$ has zero profits.

\section{Proof of Theorem 1}

According to Lemmas 2 and 4, if Sector 2 has positive output, the wage of labor and the prices of nontradeable goods are determined by the price of tradeables. Let $w^{*}$ denote this wage and let $p^{*}=\left(p_{t}, p_{n}^{*}\right)$ denote the corresponding equilibrium price variables for produced goods. Define the variable profit function for Sector 1 as $V^{1}(p *, w *, T)=\sup \left\{p_{t} y_{t}+p_{n}^{*} y_{n}+w^{*} y_{f}\right\}$ where the supremum is taken over $y$ such that $\left(y_{t}, y_{n},-T, y_{T+N+F}\right)$ is in $Y_{2}$. Since the nonproduced factors in the vector $T$ are useful only in sector 2 , it must be that in competitive equilibrium, profits in Sector 2 before the fixed factors in $T$ are paid equal $V^{1}\left(p^{*}, w^{*}, T\right)$. As Gorman (1968) showed, the vector of rental prices for the fixed factors in $T$ must be the gradient of $V^{1}(p *, w *, T)$ with respect to $T$ if this gradient exists. Gorman also showed that $V^{1}(p *, w *, T)$ is a concave function of $T$. A standard mathematical result is that a concave function is almost everywhere differentiable. Therefore for almost all values of $T$, the vector of factor prices is uniquely determined by the prices of tradeables and the endowment of factors other than labor. The function, $V^{1}(\cdot, \cdot, \cdot)$ is homogeneous of degree one in $T$. Therefore the gradient of $V^{1}(p *, w *, T)$ with respect to $T$ is homogeneous of degree zero. It follows that factor prices are left unchanged when the vector $T$ is multiplied by any positive scalar.

Proof of Corollary 1

If production in Sector 1 is strictly convex, then profits in the Sector 1 are seen to be a strictly concave function of the inputs of variable factors. It follows that there can be only one vector of variable inputs that maximize profits.

\section{Some Applications}

The model discussed above permits remarkably strong and occasionally surprising conclusions to be drawn from comparative statics analysis. It is especially easy to analyze the effects of those policies or parametric changes which turn out not to influence equilibrium wages. We consider some examples here. A slightly more elaborate analysis is needed to treat the effects of policies which result in changes in factor prices. Examples of such policies are tariffs and taxes on production. 7

\section{An Excise Tax on Consumption}

For a closed economy, general equilibrium analysis of tax incidence is very difficult. The effect of a change in taxes on equilibrium prices will in general depend

\footnotetext{
${ }^{7}$ If Sector 1 is neoclassical, it can be shown that if a small country both produces and imports the output of Sector 1, then labor unambiguously gains from an increase in tariffs. Stolper and Samuelson (1941) showed a similar result for a two factor Hecksher-Ohlin model, but suggested that their result would not extend to a model with more than two factors.
} 
on demand functions as well as on technology. The post- change tax prices will not in general be related in any simple way to the old prices and the change in taxes. For a small country satisfying our nonsubstitution theorem, however, the situation is remarkably simple. If the excise tax is only on the consumption of goods and not on their use as inputs in production processes, every step of our reasoning in the proof of Theorem 1 applies to the prices received by producers and the prices of factors. An excise tax on consumption will have no effect on any of these prices. However, the prices paid by consumers will now differ from the prices received by producers by the amount of the tax. Thus if $p^{*}$ is the vector of prices in competitive equilibrium in the absence of a tax and if $t$ is the vector of excise taxes imposed, the price vector faced by consumers in competitive equilibrium is simply $p^{*}+t$, for any $t$. Since factor prices are unaffected by $t$, incomes would not change with changes in $t$. This makes the welfare analysis of alternative government tax and expenditure policies particularly easy. All we have to do to check whether a particular consumer would prefer a vector of excise tax rates $t$ to another one, $t^{*}$, is to look at his indirect utility function and determine whether at his competitive income, he prefers the price vector $p+t$ or the price vector $p+t^{*}$.

\section{Immigration}

If the conditions of Theorem 1 are satisfied and the country produces some Sector 1 output, then the prices of all goods and factors are independent of the country's labor endowment. It follows that immigration into the country would not affect factor incomes of previous inhabitants even if the immigrants own labor services but no capital. This, surprising conclusion holds because Sector 1, which uses tradeable inputs and labor, can be expanded using the same factor proportions as it had before the immigration. Employment and output would be unchanged in industries like agriculture and mining where there is diminishing returns to labor applied to a fixed supply of nonproduced factors.

Although prices, wages, and factor input proportions do not change, there will of course be changes in some aggregate quantity statistics. The additional labor endowment will be absorbed into the nonextractive manufacturing and services sectors. Consumption of the old residents must be exactly the same as before, since factor prices and commodity prices do not change. The new residents will consume some manufactured goods, some agricultural output and some services. Since all nontradeables are produced domestically, the nontradeable sector must grow by the amount of nontradeables consumed by the immigrants. Suppose that before the immigration the country exported extractive goods and imported manufactured goods. Since extractive output remains unchanged and the immigrants consume some extractive goods, it must be that exports diminish. In competitive equilibrium, the value of exports must equal the value of imports. Since no commodity prices have changed, we deduce that imports also diminish. In sum, the country becomes less dependent on world trade as its manufacturing sector grows and its extractive sectors remain unchanged. If the country initially imported food and exported extractive output, 
the same kind of reasoning implies that agricultural imports must increase and manufacturing exports increase. Immigration, then, would increase international trade.

\section{A Minerals Boom}

Suppose that substantial deposits of oil or other valuable minerals are discovered in a small country. What will be the effects on prices and incomes? Assuming that these deposits are not large relative to world supplies so that world prices of tradeables are unaffected, Theorem 1 tells us that wages and the prices of consumption goods will not change. Therefore the minerals boom would have no effects at all on the economic welfare of a citizen whose entire income comes from the sale of labor services.

Our theorems do leave the possibility that the discovery of one mineral deposit might alter the value of another. An obvious case of this kind would be the discovery of gold in a copper mine. However, if we exclude such complementarities as is done in the specific factors model considered above, the minerals boom would not affect the prices of any factor of production. Likewise, in the general model, a proportional increase in the endowments of all factors other than labor has no effect on factor prices. It is interesting and perhaps surprising to notice that in these cases, there are no indirect gainers or losers from the minerals boom. The only gainers are the owners of the newly discovered resources.

Though wages and prices do not change, a minerals boom would, of course, have effects on output levels. These are easily analyzed in the case where all factor prices remain unchanged. With input prices unchanged, factor proportions will not change in any industry. Since the minerals sector has greater amounts of minerals deposits available, it must expand its output and its labor input in the proportion to the size of the minerals discoveries. Since factor prices are unchanged, incomes of the owners of the new discoveries will increase by the value of the discoveries valued at the old prices. Although prices of consumer goods are unchanged, if some of the new discoveries are owned by residents of the small country, there will be income effects. If nontradeables are normal goods, then demand for nontradeables will increase. Because nontradeables must be domestically produced and input coefficients are unchanged, the amount of the small country's labor used in the nontradeable sector must increase. Since the nontradeable sector and the mining sector increase their use of labor and input coefficients do not change, it follows that some of the other industries must contract.

\section{Intertemporal Analysis}

Static general equilibrium theory can be extended to the analysis of an economy over time by the simple device of introducing dated commodities. Units of a commodity presented at two different times are treated as two different commodities. In equilibrium, each commodity at each date has its own competitive 
price and the supply of each commodity at each date equals the demand for it at that date. The purpose of this section is to show how Theorem 1 can be extended so as to apply to intertemporal general equilibrium in a small trading country.

Just as market activities in a small country are assumed to have no influence on world prices of tradeables in the static model, here it is assumed that in an intertemporal economy, a small country does not influence either spot or futures prices of tradeable commodities. Stated in another way, we assume that the world own rate of interest on each tradeable commodity at each time period is determined externally to a small country. It might seem that with this assumption and with the trick of dating commodities, the results of Theorem 1 would carry over directly to intertemporal competitive equilibrium. However, this doesn't quite work. Assumptions 1-3, when interpreted for an intertemporal economy, are quite unsatisfactory. In particular, Assumptions 2 and 3 require that Sectors 2 and 3 use only one nonproduced factor of production, labor. But in an intertemporal economy, labor services presented at different times must be treated as different commodities. Certainly it would be unreasonable to assume that labor can be used in the nontradeable sector only in one time period.

This difficulty can be resolved by an extension of Theorem 1. In the static model treated in Theorem 1, if Sectors 2 and 3 are active, the zero profit conditions for these sectors determine the wage rate. Where there are several time periods, this result extends as follows. ${ }^{8}$ If Sectors 2 and 3 produce some output in each period, the wage of labor in each period will be determined by the zero profit conditions for producing output in that time period. All sectors can be allowed to use labor at any time period as an input and to produce their outputs in any period. The same reasoning that led to a proof of Theorem 1 will show that wage rates and the prices of nontradeables in each period are determined are determined by the prices of tradeables.

Another problem that arises in extending Theorem 1 to an intertemporal economy is the treatment of durable plant and equipment. For example, factory buildings in place are not internationally tradeable. Furthermore at any moment, the number of factories in place is fixed, but the number of factories in place in the future can be changed by current activities. A more detailed model should treat initial stocks of capital goods as factors in fixed supply. Stocks of durable capital goods that appear in the future are subject to economic decisions and should be treated as joint products of production activities. The assumptions made here about Sector 1 are consistent with such a model. Sector 1 can have any number of fixed factors and can produce joint products in very general ways. Although we assumed that Sector 1 has no nontradeable outputs, this assumption does not preclude individual firms in Sector 1 from being net sellers of used plant and equipment. All that is required is that any such sales are within Sector 1. This will be a reasonable assumption if those items of second-hand plant and equipment from Sector 1 that can not be traded

\footnotetext{
${ }^{8}$ To avoid mathematical complications, we will confine our attention to a model in which the number of time periods is finite. Infinite horizons could be introduced without changing the results seriously.
} 
internationally are not useful in Sectors 2 and 3.

Our discussion has so far concerned the degree of generality under which a nonsubstitution result obtains in intertemporal general equilibrium. Now that we know conditions that imply a nonsubstitution result, it is interesting to study circumstances in which nonsubstitution does not hold. While Assumptions 1-3 permit Sector 1 to use durable capital and equipment in very general ways, they do not allow either joint products or nonproduced factors other than labor in the nontradeable sector. Sector 2 is allowed to produce joint products but is not permitted either to use nonproduced factors other than labor. This rules out the use of durable capital in Sector 2 unless its used capital goods are internationally tradeable. If nontradeable second-hand capital goods are important in all manufacturing sectors, then the factor price equalization theory that we have expounded might be a useful long run characterization but in the short run, all industries would have some specific factors. Models incorporating short and long run industry structure in this way could yield an interesting theory of economic fluctuations.

\section{Conclusion}

In this paper we demonstrate that wages and the prices of nontradeables will be equalized among countries with very different factor endowments and patterns of demand even if the number of nontraded factors exceeds the number of traded goods. Our results differ from the standard factor-price equalization theorems because we do not seek conditions that equalize the rewards of all factors. Instead we find conditions that allow equilibrium conditions to be decomposed in such a way as to determine wages and the prices of all nontradeable outputs independently of endowments. We make the strong assumption that the nontraded sector and at least one active traded sector in the economy use no nonproduced factors other than labor. The strategy of finding factor price equalization for some but not all factors could be extended in several ways. For example, it could be assumed that there is one sector which uses $k>1$ nonproduced factors, produces $k$ nonproduced outputs and which satisfies the usual conditions for invertibility of cost functions. The remainder of the economy could be modelled in such a way that the other prices in the system can be found, once the prices of these $k$ factors are determined. These considerations suggest that nonsubstitution theorems, if not factor price equalization theorems, are less delicate than is commonly believed, while the tendency toward international equalization of competitive wages is stronger than is usually thought to be the case. 


\section{REFERENCES}

Diewert, W. E., "Functional Forms for Profit and Transformation Functions", International Economic Review, 10, (June, 1973), pp. 284-316

Gorman, W. M.,(1968) "Measuring the Quantities of Fixed Factors", in Value, Capital, and Growth, Papers in Honour of Sir John Hicks, edited by J. N. Wolfe (Edinburgh: Edinburgh University Press,1968)

Komiya, R. (1967) "Nontraded Goods and the Pure Theory of International Trade",International Economic Review, 8-2, (June, 1967), pp. 132-152

McKenzie, Lionel W. (1955) "Equality of Factor Prices in World Trade", Econometrica, 23, July, 1955

Samuelson, Paul A., and Stolper, Wolfgang F.,(1941) "Protection and Real Wages", The Review of Economic Studies, Vol IX, (November, 1941), pp. 58-73.

Samuelson, Paul A. (1948) "International Trade and the Equalization of Factor Prices", Economic Journal vol LVIII (June 1948) pp. 181-197.

Samuelson, Paul A. (1951) "Abstract of a Theorem Concerning Substitutability in Open Leontief Models", in Activity Analysis of Production and Allocation, edited by T. C. Koopmans (New York: Wiley, 1951).

Samuelson, Paul A. (1961) "A New Theorem on Nonsubstitution", in Money, Growth, and Methodology, published in honor of Johan Akerman, Vol 20, Lund Social Science Studies (Lund, Sweden: CWK Gleerup, 1961), pp.407-423.

Samuelson, Paul A. (1971) "Ohlin Was Right" The Swedish Journal of Economics, Vol 73 (December, 1971), pp. 365-384.

Woodland, A. D. (1977) "Joint Outputs, Intermediate Inputs, and International Trade Theory" International Economic Review, 18, (October, 1977), pp.517-533 